УДК 622.24

\title{
СОВЕРШЕНСТВОВАНИЕ ТЕХНОЛОГИИ ОЧИСТКИ ЗАБОЯ ВОЗДУХОМ ДЛЯ СНИЖЕНИЯ АВАРИЙНОСТИ ПРИ БУРЕНИИ СКВАЖИН НА КУЮМБИНСКОМ НЕФТЯНОМ МЕСТОРОЖДЕНИИ
}

\author{
Бузанов Кирилл Владимирович1, \\ byzanovaltay@mail.ru \\ Борисов Константин Иванович2, \\ kibor1956@gmail.com \\ 1 Национальный исследовательский Томский политехнический университет, \\ Россия, 634050, г. Томск, пр. Ленина, 30. \\ 2 Сибирский федеральный университет, \\ Россия, 660041, г. Красноярск, пр. Свободный, 79/10.
}

\begin{abstract}
Актуальность. Проблема поглощений промывочной жидкости при строительстве верхних секций эксплуатационных и разведочных скважин на месторождениях Восточной Сибири не нова и является одной из основных причин низкого показателя коммерческой скорости бурения в регионе. Кроме того, проходка осложненных интервалов скважин требует значительных временных и материальных затрат. Одним из перспективных решений проблемы поглощений промывочной жидкости является применение воздуха в качестве очистного агента. Технология бурения скважин с продувкой известна более ста лет, однако в связи с прогрессом в области компрессорного машиностроения открываются новые горизонты и возможности её применения. При этом требуется адаптация существующих методик расчета воздухоснабжения к новым для данной технологии горно-геологическим условиям. В статье изложены основные результаты научно-практического исследования очистки забоя воздухом при бурении интервалов под кондуктор в горно-геологических и хозяйственных условиях Куюмбинского нефртяного месторождения.

Цель: формирование основ технико-технологического решения, обеспечивающего безаварийную проходку интервалов скважин под направления и кондукторы с применением очистки забоя воздухом на месторождениях Восточной Сибири.

Объект: методика расчета воздухоснабжения циркуляционной системы скважины Б.Б. Кудряшова.

Методы: теоретические исследования, математическое моделирование с заимствованием положений теории пневмотранспорта, аэродинамики дисперсных частии в потоке воздуха, производственный эксперимент в условиях действующей буровой установки на месторождении.

Результаты. Сформулированы положения, позволяющие модисфицировать расчетную методику воздухоснабжения циркуляционной системы скважины, применение которых позволит предотвратить аварийно-опасные ситуации на стадии проектирования.
\end{abstract}

\section{Ключевые слова:}

Очистка забоя воздухом, аэродинамическое сопротивление, методика Б.Б. Кудряшова,

катастрофические поглощения промывочной жидкости, регулирование параметров режима бурения,

аэродинамическое давление в скважине.

\section{Введение}

Нефтегазовая промышленность является важнейшей народнохозяйственной отраслью в структуре промышленного производства России. Осуществляя транснациональные и внутренние проекты, нефтяникам приходится решать широкий спектр проблем в различных условиях ведения работ. Характерным примером таких проблем являются катастрофические поглощения промывочной жидкости при бурении интервалов под направления и кондукторы на скважинах месторождений Восточно-Сибирского региона Эффективность решений зависит от совокупности факторов: автономности месторождения, развития его инфраструктуры, наличия поверхностных источников водозабора, уровня организации производства компании-оператора месторождения.

Так, например, благодаря близости рек и некоторым организационным решениям проблема катастрофических поглощений решена при строительстве секции кондуктора на Ярактинским и Талаканском месторождениях.
Однако практика ведения работ на Чаяндинском месторождении (Якутия) [1], Дулисьминском (Иркутская область) [2], Куюмбинском (Красноярский край) [3] месторождениях показывает сложность, а зачастую и невозможность ликвидации поглощений очистного агента на водной основе в интервалах направлений и кондукторов и значительные, сопряженные с этим, временные и ресурсные затраты.

Строительство секций кондукторов и технических колонн на разведочных скважинах Ковыктинского месторождения (Иркутская область) также ведется в условиях естественного отсутствия циркуляции промывочной жидкости. Вследствие этого только лишь на одной скважине № $74 p$ время углубления интервала под кондуктор составило более 35 суток. Осложняющим фактором является и ограниченность водоснабжения на месторождении. В табл. 1 приведен анализ производственной ситуации на скважине № 74p Ковыктинского газоконденсатного месторождения. 
Таблица 1. Анализ производственной ситуащии на скважине № 74р Ковыктинского ГКМ

Table 1. Analysis of operational situation for well № $74 \mathrm{r}$ of Kovyktinskoe gas condensate field

\begin{tabular}{|c|c|c|}
\hline $\begin{array}{c}\text { Забой на момент поглощения, м } \\
\text { Bottom hole depth at the moment } \\
\text { of fluid loss, } \mathrm{m}\end{array}$ & $\begin{array}{c}\text { Параметры режима } \\
\text { бурения } \\
\text { Drilling parameters }\end{array}$ & $\begin{array}{c}\text { Описание производственной ситуации } \\
\text { Operational situation }\end{array}$ \\
\hline 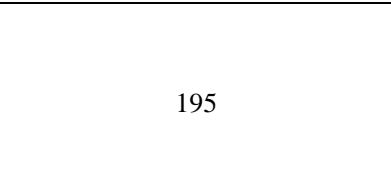 & $\begin{array}{l}\mathrm{n}=60 \div 65 \text { об/M/rpm; } \\
\mathrm{W}_{\text {дол/bi }}=40 \div 50-120 \text { кH/kN; } \\
\mathrm{Q}_{\text {вх } / \text { inc }}=28-18 \mathrm{\pi} / \mathrm{c} / \mathrm{hp} ; \\
\mathrm{V}_{\text {ср.мex/av.pen }}<1 \mathrm{M} / \mathrm{u} / \mathrm{m} / \mathrm{h}\end{array}$ & $\begin{array}{l}\text { Катастрофическое поглощение, } \rho=1,08 \div 1,12 \text { г } / \mathrm{cm}^{3} \text {, более } 20 \text { операций } \\
\text { ГИМ-поршень, цикличные закачки вязкоупругой смеси в объеме } \\
56 \mathrm{~m}^{3}, \text { фактическое время бурения интервала } 29-339 \mathrm{M}-35 \text { суток } \\
\text { Catastrophic loss, } \rho=1,08 \div 1,12 \mathrm{~g} / \mathrm{cm}^{3}, \text { over } 20 \text { stokes of hydraulic actua- } \\
\text { tor piston, periodic pushing of hi-vis pill } \mathrm{V}_{\text {total }}=56 \mathrm{~m}^{3}, 29-339 \mathrm{~m} \text { interval } \\
\text { drilling time - } 35 \text { days }\end{array}$ \\
\hline
\end{tabular}

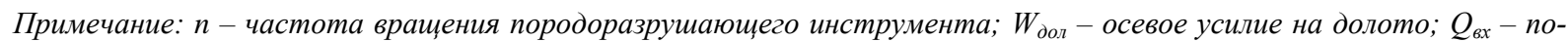
дача промывочной жидкости; $V_{\text {срмех }}$ средняя механическая скорость бурения; $\rho$ - плотность промывочной жид-

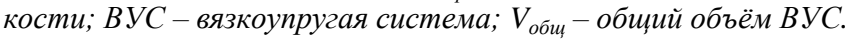

Note: $n$ - rotation speed of the rock cutting tool; $W_{\text {bit }}$ - axial weight on the drilling bit; $Q_{i n c}$-flow rate of the flushing fluid; $V_{\text {av.pen }}$ - average penetration rate; $\rho$-flushing fluid density; hi-vis - high viscosity; $V_{\text {total }}$-total volume of the hi-vis pill.

С конца прошлого века зарубежные и отечественные специалисты активно работают в направлении увеличения эффективности ударно-вращательного бурения с продувкой воздухом или газожидкостными смесями. Широкое распространение получили исследования в области технологии и техники пневмоударного бурения, такие как:

1) повышение рабочего давления воздуха на основе создания высокопроизводительных бустеров и современных буровых установок;

2) создание погружных пневмоударных установок с улучшенными эксплуатационными характеристиками, энергетическими параметрами и ресурсом работы [4-6].

С целью сокращения срока строительства скважин и повышения эффективности процесса сооружения горных выработок компании ООО «Интес» и ООО «Коралайна Инжиниринг» провели опытнопромышленные работы по строительству секций кондукторов с использованием технологии ударновращательного бурения и очистки забоя воздухом на эксплуатационных скважинах Куюмбинского месторождения.

Эти и другие достижения в области материаловедения, механики газожидкостных сред, опыта отечественного и зарубежного, теории и практики технологии бурения скважин с очисткой забоя воздухом и конструкторских решений определяют современный мировой технический уровень развития ударновращательного бурения, существенно расширив технические и технологические возможности его применения.

Использование воздуха как очистного агента является перспективной для исследования технологией снижения проблемы катастрофических поглощений при бурении интервалов под направление и кондуктор в контексте реализации ударно-вращательного бурения.

Однако анализ опыта отечественного и зарубежного, теории и практики технологии бурения скважин с очисткой забоя воздухом показывает целесообразность дальнейшего развития способа и актуальность научных исследований в следующих направлениях:
1) Определение достоверной зависимости для расчета коэффициента аэродинамического трения в условиях повытенных расходов очистного агента.

2) Выявление степени влияния шероховатости затрубного пространства, действительной массовой, объемной конщентрации, а также плотности забойной примеси в потоке воздуха на ожидаемое давление на компрессоре.

3) Создание методики оптимизащии механической скорости бурения и расхода очистного агента.

4) Проведение расчетов и мониторинг рабочего аэродинамического давления в циркуляционной системе для предотвращения пневморазрыва горных пород разреза скважины.

\section{Выбор зависимости для определения коэффициента аэродинамического трения}

Для оценки требуемого воздухоснабжения скважины первостепенную важность имеет правильный выбор зависимости для расчета коэффициента аэродинамического сопротивления.

Проведенные исследования показали принципиальную возможность совершенствования методики расчета воздухоснабжения, предложенной Б.Б. Кудряшовым, на основе использования теории пневмотранспорта и динамики движения дисперсных частиц в несущем газовом потоке [7].

$\mathrm{B}$ частности, для учета действительной объемной концентрации забойной примеси и вязких сил используется формула определения кинематической вязкости потока воздуха $v_{p}[8]$ :

$$
\mathrm{v}_{\mathrm{p}}=\mathrm{v}_{\mathrm{g}} \cdot\left(1-\frac{\mu_{\mathrm{v}}}{0,65}\right)^{-1,675},
$$

где $\mu_{v}$ - объемная концентрация частиц горной породы (или притока воды); 0,65 и -1,675 - эмпирические коэффициенты; $\mathrm{v}_{\mathrm{g}}-$ кинематическая вязкость воздуха.

В случае применения бурильных труб с ниппельным соединением Б.Б. Кудряшовым экспериментально доказана рациональность использования формулы Веймаута для расчета коэффициента аэродинамического трения [9]:

$$
\lambda_{\mathrm{B}}=\frac{0.009407}{\sqrt[3]{\bar{D}_{3 \phi}}}
$$


и формулы Лобаева при использовании труб с муфтово-замковыми соединениями [9]:

$$
\lambda_{Л}=\frac{1.42}{\left[\left(\frac{D_{\ni \phi}}{\mathrm{e}}\right) \cdot \lg \left(\mathrm{N}_{\mathrm{R}}\right)\right]},
$$

где $\lambda_{\mathrm{B}}, \lambda_{\text {л }}-$ коэффициенты аэродинамического трения; $\mathrm{D}_{\text {эф }}$ - эффективный диаметр канала; e - шероховатость стенки затрубного пространства; $\mathrm{N}_{\mathrm{R}}$ - число Рейнольдса; 0,009407, 1,42 - эмпирические коэффициенты.

В технологии бурения с контролем давления при определении потерь аэродинамического давления используют формулу Хэйланда [10-12]:

$$
\lambda_{\mathrm{X \ni}_{\ni}}=\left(\frac{1}{-1.8 \cdot \lg \left(\left(\frac{\mathrm{e}}{3.7 \cdot \mathrm{D}_{\ni \phi}}\right)^{1,11}+\frac{6,9}{\mathrm{~N}_{\mathrm{R}}}\right)}\right)^{2},
$$

где $\lambda_{\text {Хэ }}$ - коэффициент аэродинамического трения.

В.И. Марон в исследованиях динамики двухфазных потоков в трубопроводах при $N_{R}>10^{4}$ рекомендует использовать для определения коэффициента аэродинамического трения формулу И.Е. Ходановича [13]:

$$
\lambda_{X}=0,067 \cdot\left(2 \cdot \frac{\mathrm{e}}{\mathrm{D}_{э \phi}}+\frac{158}{\mathrm{~N}_{\mathrm{R}}}\right)^{0.2},
$$

и формулу А.Д. Альтштуля [13]:

$$
\lambda_{\mathrm{A}}=0,11 \cdot\left(\frac{\mathrm{e}}{\mathrm{D}_{э \phi}}+\frac{68}{\mathrm{~N}_{\mathrm{R}}}\right)^{0.25} .
$$

Для выявления степени влияния плотности продуктов разрушения забоя на результирующее расчетное давление на компрессоре нами проводились исследования для двух ситуаций: наличие только дисперсной фазы в потоке воздуха при отсутствии водопритока и с учетом поступающего в скважину водопритока, но без наличия твердой фазы.

При этом модификация методики Б.Б. Кудрямова предполагает применение в формируемых математических моделях расчета воздухоснабжения скважины зависимости Кондратьева для определения кинематической вязкости и приведенных зависимостей для расчета коэффициента аэродинамического трения.

Рассмотрим пример расчета для следующих компонентов бурильной колонны. Набор компоновки низа бурильной колонны (КНБК) включал в себя буровое долото CONCAVE SD 12 BIT (диаметр - 394 MM), погружной пневмоударник МАСН 122 (диаметр - 240 мм), УБТ-229 мм (длина - 9,4 м), переводник Н3-171/М3-152, центратор (диаметр - 374 мм), переводник Н3-152/М3-133, бурильных труб СБТ - 127 мм. Кроме этого, в колонну бурильных труб включались обратные клапаны с интервалом 27 м для предотвращения пневмоудара в момент подачи воздуха после спуско-подъемных операций.

В табл. 2, 3 приведены, соответственно, характеристики процесса углубления интервала под кондуктор на скважине № 401 и анализ производственной ситуации с помощью модифицированной нами методики [14].
Таблица 2. Характеристика бурения интервала под кондуктор скважины № 401 Куюмбинского

\begin{tabular}{|c|c|c|c|c|c|c|}
\hline 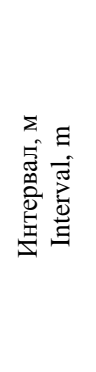 & 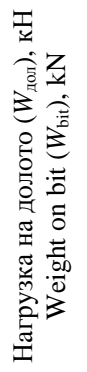 & 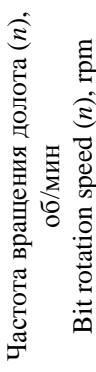 & 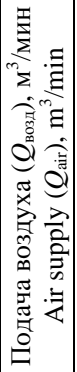 & 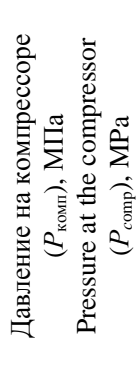 & 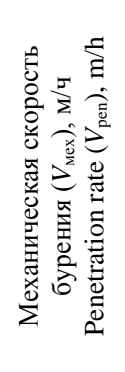 & 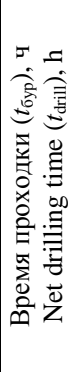 \\
\hline $34-44$ & 20 & 20 & 76 & 1,3 & 10 & 1 \\
\hline $42-66$ & $20-30$ & 20 & 76 & 1,7 & 11 & 2,2 \\
\hline $60-66$ & 5 & 20 & 76 & 1,7 & - & 1,5 \\
\hline $66-75$ & $20-30$ & 20 & 76 & 1,7 & 9 & 1 \\
\hline $70-75$ & 5 & 20 & 76 & 1,7 & - & 1,5 \\
\hline $75-90$ & $20-30$ & 20 & 76 & 1,7 & $10-11$ & 1,5 \\
\hline $85-90$ & 5 & 20 & 76 & 1,7 & - & 1,5 \\
\hline 94-118 & $\approx 40$ & 20 & 76 & $1,8-1,9$ & До $30 \mathrm{~m} / \mathrm{ч}$ & 1 \\
\hline
\end{tabular}
месторождения

Table 2. $\quad$ Parameters of drilling down the surface casing interval of well no. 401 at Kuyumbinskoe field

Таблица 3. Анализ производственной ситуации на скважине № 401 на основе модифищирован-

\begin{tabular}{|c|c|c|c|c|c|}
\hline \multirow[t]{2}{*}{$\begin{array}{c}\text { Характеристика } \\
\text { объекта исследова- } \\
\text { ния } \\
\text { Description of the } \\
\text { object }\end{array}$} & \multicolumn{5}{|c|}{$\begin{array}{c}\text { Расчетное давление при анализируемых } \\
\text { коэффициентах аэродинамического } \\
\text { трения, МПа } \\
\text { Calculated pressure at various aerodyne- } \\
\text { mic friction, MPa }\end{array}$} \\
\hline & $\lambda_{\mathrm{B}}$ & $\lambda_{\text {л }}$ & $\lambda_{X_{9}}$ & $\lambda_{\mathrm{x}}$ & $\lambda_{\mathrm{A}}$ \\
\hline $\begin{array}{l}\text { Выкидная линия } \\
\text { Flow line }\end{array}$ & 0,1037 & 0,1013 & 0,1054 & 0,1053 & 0,1055 \\
\hline $\begin{array}{l}\text { Забой направления } \\
35 \text { м } \\
\text { Surface casing bottom } \\
\text { hole } 35 \mathrm{~m}\end{array}$ & 0,1041 & 0,1013 & 0,1061 & 0,1059 & 0,1062 \\
\hline $\begin{array}{l}\text { Забой } 94 \text { м } \\
\text { Bottom hole } 94 \text { m }\end{array}$ & 0,1042 & 0,099 & 0,1087 & 0,1079 & 0,1086 \\
\hline $\begin{array}{l}\text { Koмпресcop } \\
\text { Compressor } \\
\end{array}$ & 1,577 & 1,55 & 1,66 & 1,59 & 1,61 \\
\hline
\end{tabular}
ной методики

Table 3. Analysis of operational situation at well no. 401, based on the modified method

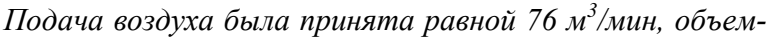
ная кониентрачия водопритока в потоке воздуха принята в соответствии с геологическими условиями Куюмбинского месторождения и составила $2,8 \cdot 10^{-3}$, объемная концентрация горной породь $-1,34 \cdot 10^{-4}$. Забой 94 м принят как достигнутый в штатном режиме на скважине во время опытно-промышленных работ.

Air supply was taken at $76 \mathrm{~m}^{3} / \mathrm{min}$, volumetric concentration of water influx in the air flow was taken at $2,8 \cdot 10^{-3}$, based on the geological conditions for Kuyumbinskoe field, volumetric concentration of rock $-1,34 \cdot 10^{-4}$. Bottom hole at the depth of $94 \mathrm{~m}$ was taken as actual, reached normally during the pilot work at the well.

Анализ данных табл. 2, 3 показывает, что наибольшую точность расчетов воздухоснабжения скважины обеспечивает использование коэффициента

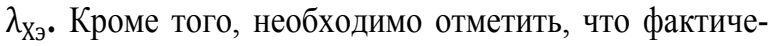
ски реализованный на скв. № 401 расход воздуха в циркуляционной системе недостаточен для эффек- 
тивного удаления выбуренной породы с забоя скважины. Для оценки необходимого расхода воздуха нами проведены расчеты с использованием основных положений методики Б.Б. Кудряшова и теории пневмотранспорта и построены математические модели воздухоснабжения для условий ведения работ на Куюмбинском нефтяном месторождении. Значения расходов $Q_{\text {возд }}=166 \mathrm{~m}^{3} /$ мин и $Q_{\text {возд }}=216 \mathrm{~m}^{3} /$ мин были получены для скорости витания частиц 15,25 м/с и транспортной скорости потока 19,2 м/с, соответственно [14].

Таким образом, модифицированная методика расчета воздухоснабжения ичиркляционной системь разведочных скважин для условий Куюмбинского месторождения позволяет:

1) повысить точность расчета требуемого рабочего давления на компрессоре до $98 \%$;

2) учесть наличие продуктов разрушения забоя в потоке воздуха благодаря использованию характеристик кинематической вязкости;

3) аналитически оценить закономерности изменения рабочего давления на забое скважины при повышении расхода воздуха на компрессоре до эффективных значений.

\section{Разработка критерия расходной}

массовой концентрации шлама

Проведение промышленных испытаний технологии ударно-вращательного бурения на эксплуатационных скважинах Куюмбинского месторождения позволило выявить важность известного параметра расходной массовой концентрации шлама для стабильности процесса углубки скважины [9]:

$$
\begin{gathered}
\mu=G_{\text {п }} / G, \\
G=\frac{Q \cdot p_{0}}{R \cdot T}, \\
G_{\text {п }}=\frac{\pi \cdot D_{\text {бК }}^{2} \cdot \rho \cdot V_{\text {Mex }}}{4},
\end{gathered}
$$

где $\mu$ - расходная массовая концентрация шлама в потоке воздуха; $G_{\text {п }}$ - удельная масса выносимой горной породы, кг/с; $G$ - массовый расход воздуха, нагнетаемого в скважину, кг/с; $Q$ - расход воздуха, $\mathrm{m}^{3} / \mathrm{c} ; p_{o}$ - атмосферное давление, Па; $R$ - газовая постоянная воздуха, Дж/кг ${ }^{\circ} \mathrm{K} ; T-$ средняя температура воздуха в скважине, К; $D_{\text {бк }}$ диаметр формируемого ствола скважины, м; $\rho$ - средняя плотность горных пород, кг $/ \mathrm{m}^{3} ; V_{\text {мех }}$ - планируемая механическая скорость бурения интервала под направление, м/с.

Анализ результатов производственного эксперимента на скважине № 401 Куюмбинского месторождения выявил увеличение расходной массовой концентрация (РМК) забойной примеси в потоке воздуха с 2 до 3,1 при росте $V_{\text {мех }}$ с 10 до 30 м/ч и неизменном расходе воздуха $Q_{\text {возд }}=76 \mathrm{~m}^{3} /$ мин. При этом через час ведения работ по углублению в таких условиях был получен рост давления на $1,5-2$ кгс/см² ший первым признаком прихвата/прижога КНБК. При бурении интервала под кондуктор скважины № 404 значение показателя РМК шлама в потоке воздуха составило 1,86. Время углубки при этом -
8,5 часов, время продувки без углубления - 2 часа. Для аналогичного интервала скважины № 405 значение показателя РМК шлама в потоке воздуха составило 2,04. Бурение при этом составило 6 часов, время продувки без бурения - 2 часа. Критерием безаварийности в данном случае нами предлагается использовать значение показателя расходной массовой концентрации продуктов разрушения забоя скважины в потоке очистного агента, полученное эмпирически при определенных значениях механической скорости бурения, а также соотношениях времени углубления и продувки забоя.

На рис. 1 приведен график, отображающий закономерность распределения значений критерия РМК от механической скорости и времени углубления.

Результаты проведенных ранее исследований говорят о невозможности корректного учета влияние значения РМК шлама на величину рабочего давления на компрессоре при проектировании воздухоснабжения циркуляционной системы [1-3].

В условиях проведения опытно промышленных работ (ОПР) стабильность процесса бурения наблюдалась при значении $\mathrm{PMK}=2$ и соотношении времени углубления и продувки 6,5 ч/3,5 ч.

Систематизация полученных данных дает возможность ввести критериальную оценку стабильности процесса углубки интервалов скважин под кондуктор на исследуемом месторождении на основе поддержания значения показателя РМК равным 2, соотношения времени бурения и чистки забоя при поэтапном увеличении расхода воздуха и механической скорости бурения.

Оптимальное регулирование параметров режима бурения $V_{\text {мех }}$ и $Q_{\text {возд }}$ при проходке интервала под кондуктор скважины № 401 Куюмбинского месторождения представлено на рис. 2.

\section{Методика расчета аэродинамических давлений с учетом пластовых условий}

Достижения в области повышения надежности конструкций погружных пневмоударников и компрессорном машиностроении сделали возможным обеспечение повышенного расхода воздуха при очистке забоя скважины. Вместе с тем возросли риски возникновения ситуации пневморазрыва пласта. Инициирование пневморазрыва может привести к различным негативным последствиям, таким как скапливание продуктов разрушения в призабойной зоне, вторичное измельчение шлама, грифоны.

А.С. Бронзов, В.И. Тиль, М.Н. Климентов $[15,16]$ отмечают факты бурения геолого-разведочных скважин с продувкой воздухом в отсутствии циркуляции на устье и, как следствие, выноса шлама. В ряде случаев отсутствие выноса породы может оказывать на стабильность углубки положительное влияние. При значительной трещиноватости горных пород происходит кольматация трещины, улучшается целостность ствола скважины и снижается риск возможных поглощений тампонажного раствора при заканчивании секции. 
Известия Томского политехнического университета. Инжиниринг георесурсов. 2020. Т. 331. № 2. 92-101

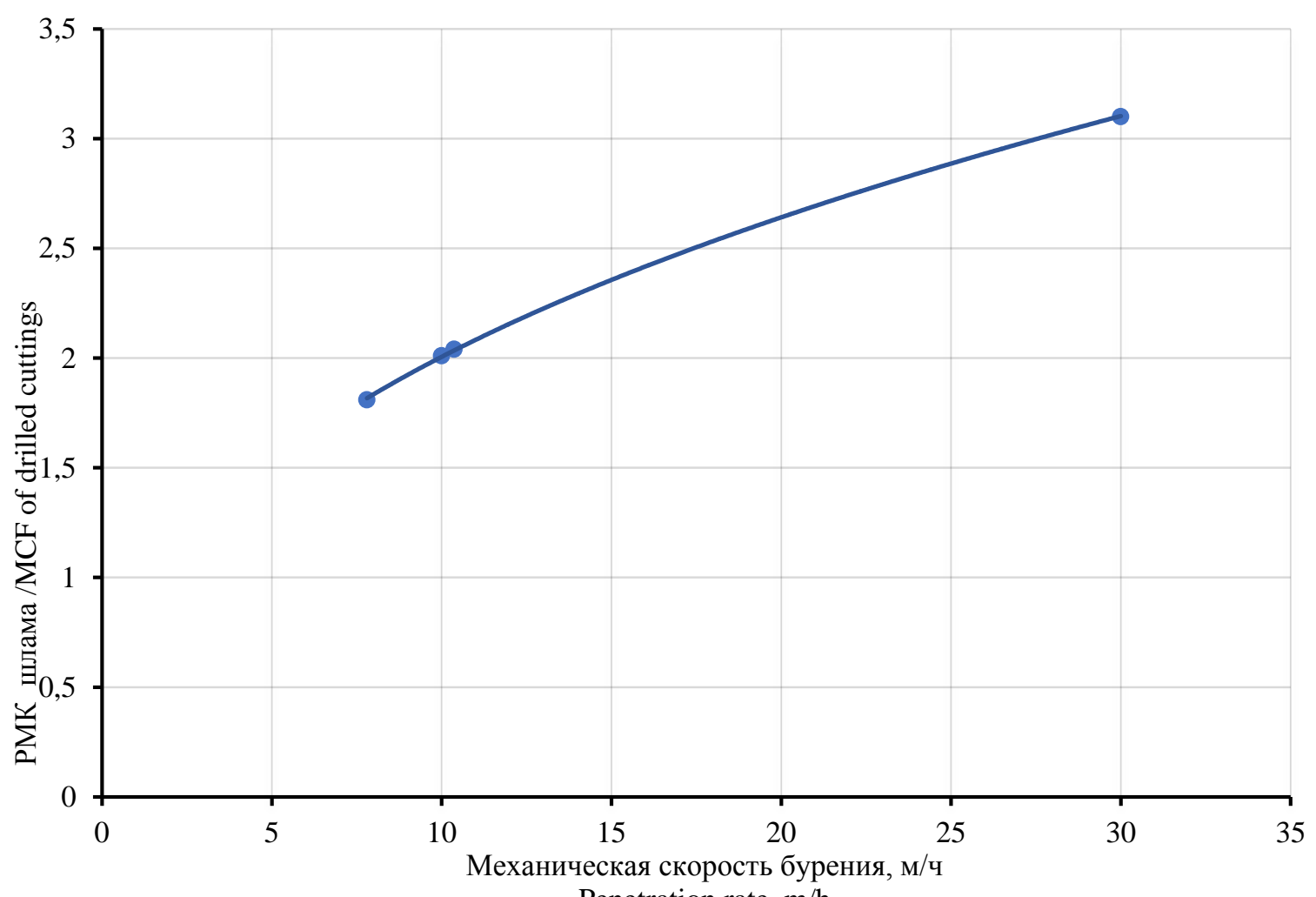

Penetration rate, $\mathrm{m} / \mathrm{h}$

Pис. 1. Значения расходной массовой концентрации при соответствующиих $V_{\text {мех }}$ на скважинах № 401, 404, 405 Куюмбинского нефтяного месторождения

Fig. 1. Values of mass concentration in the flow and corresponding values of $V_{\text {pen }}$ in wells no. 401, 404, 405 of Kuyumbinskoe oilfield

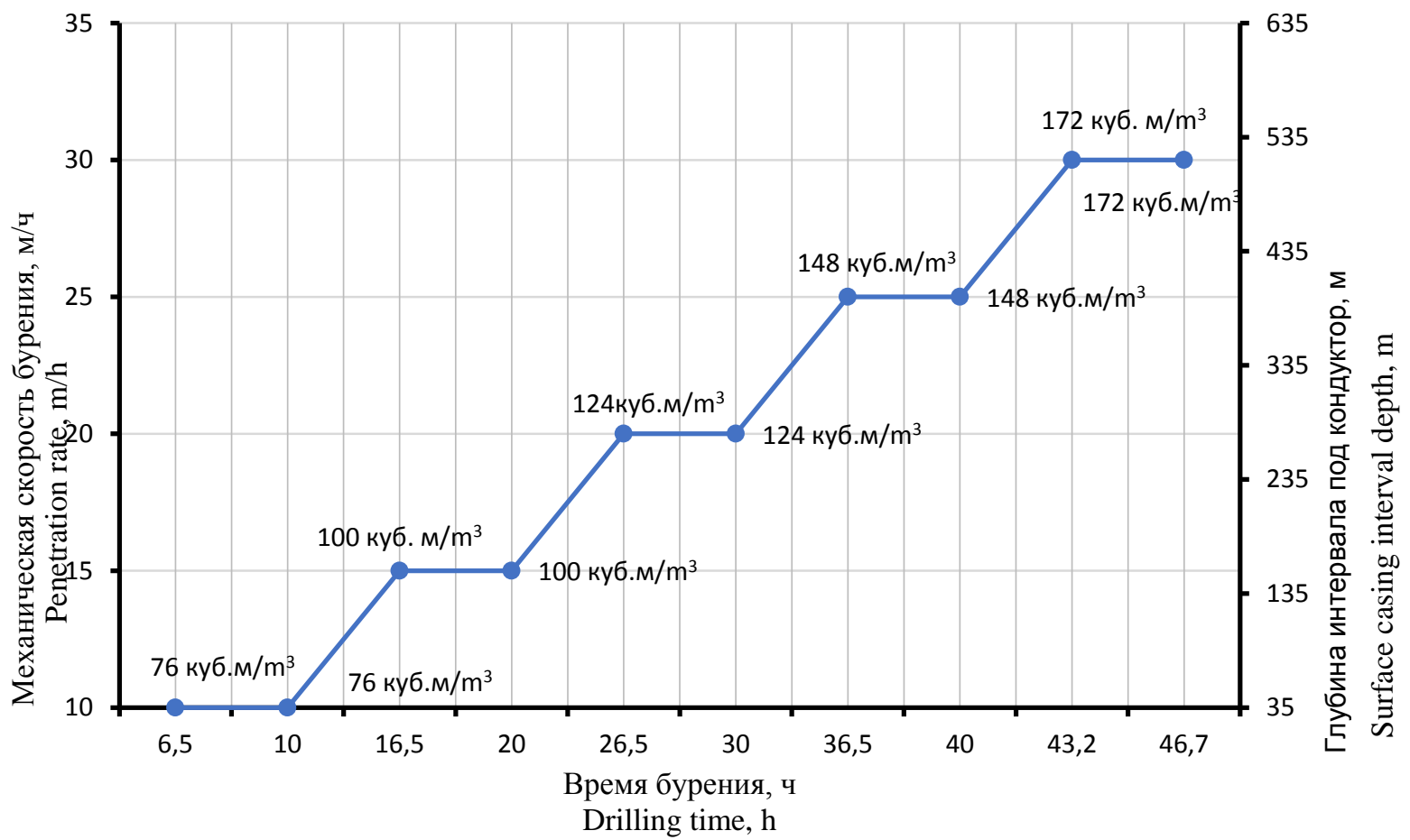

Рис. 2. Регулирование $V_{\text {мех }}$ и $Q_{\text {возд }}$ при постоянном значении критерия РМК=2 и соотношения времени углубления и продувки

Fig. 2. Control of $V_{p e n}$ and $Q_{\text {air }}$ at constant $M C F=2$ and the ratio of penetration time and blow-down 
Предлагаемые методики расчета воздухоснабжения [9, 11, 17-19] позволяют рассчитывать параметры работы циркуляционной системы, не учитывая при этом давлений в системе скважина - пласт. Зависимость для расчета требуемого расхода воздуха, предлагаемая в методике Б.Б. Кудряшова [9], не учитывает сменяемость горных пород по разрезу скважины.

$$
Q_{\text {возд }}=\left(K \cdot K_{1} \cdot \frac{\pi\left(D_{\text {скв }}^{2}-D_{\text {бК }}^{2}\right)}{4}\right) \cdot V,
$$

где $Q_{\text {возд }}$ - расход воздуха, $\mathrm{m}^{3} / \mathrm{c} ; K-$ коэффициент, учитывающий уменьшение подъемной силы воздуха вследствие потерь давления в кольцевом пространстве; $K_{1}-$ коэффициент неравномерности скорости из-за наличия каверн; $V$ - скорость восходящего потока воздуха, м/с; $D_{\text {скв }}$ - диаметр скважины с учетом его увеличения вследствие разработки, м; $D_{\text {бк }}$ диаметр бурильных труб, м.

На этом фоне приобретает важность решение задачи по созданию научной основы проектных расчетов ичиркулячионной системь скважины, позволяющчих предотвратить искусственный пневморазрыв горных пород.

Базой являются предложенные Б.Б. Кудряшовым формулы для определения аэродинамических сопротивлений [9].

Для кольцевого пространства:

$$
P=\frac{\sqrt{p_{1}^{2}+\lambda \cdot\left(1+K_{\Gamma} \cdot \mu\right) \cdot a \cdot l}+p_{1} \cdot(1+\mu) \cdot b \cdot l}{1-(1-\mu) \cdot b \cdot l},
$$

где $p_{1}$ - давление на предыдущей ступени расчета, Па; $\mu$ - расходная концентрация шлама в потоке воздуха; $K_{\Gamma}$ - безразмерный коэффициент Гастерштадта; $l$ текущая координата для восходящего потока от устья к забою, м; $\lambda$ - коэффициент аэродинамического трения; $a, b$ - выражения, применяемые с целью эргономики расчетов:

$$
\begin{aligned}
& a=\frac{G^{2} \cdot R \cdot T}{D_{\text {вых }} \cdot F^{2}}, \\
& b=\frac{g \cdot \sin \beta}{2 \cdot R \cdot T},
\end{aligned}
$$

где $D_{\text {вых }}-$ внутренний диаметр канала движения воздуха, м; $G$ - массовый расход воздуха, кг/с; $R$ - газовая постоянная воздуха, Дж/кг ${ }^{\circ} \mathrm{K} ; F-$ площадь сечения канала, м²; $g$ - ускорение свободного падения, $\mathrm{M} / \mathrm{c}^{2} ; \beta$ - зенитный угол скважины, град.

Также при нисходящем движении потока воздуха по бурильной колонне:

$$
p_{\text {бк }}=\frac{\sqrt{p_{1}^{2}+\lambda \cdot a \cdot\left(l+\frac{D_{э \phi} \cdot \xi \cdot n}{\lambda}\right)}-p_{1} \cdot b \cdot l}{1+b \cdot l},
$$

где $n$ - количество замковых соединений в бурильной колонне; $\xi$ - коэффициент местного сопротивления в соединении бурильного инструмента, определяющийся в свою очередь по формуле Б.С. Филатова:

$$
\xi=a^{\prime} \cdot\left[\left(\frac{D_{э \phi}}{d_{3}}\right)^{2}-1\right]^{2},
$$

где $a^{\prime}-$ опытный коэффициент для муфтовозамковых соединений принимается равным $2 ; d_{3}-$ наименьший диаметр суженной части соединения, м.
Сущность предлагаемых дополнений заключается в поинтервальном расчете аэродинамических давлений на основе стратиграфических границ разреза и значений эффективного расхода воздуха (рис. 2). Далее определяются граничные условия: пластовое давление, давление гидроразрыва, что позволяет оценить расчетное рабочее давление. Принимается во внимание и возможность регулирования рабочего давления на компрессоре. Необходимо заметить, что современные дожимные компрессорные установки позволяют регулировать давление в скважине с достаточно высокой точностью.

Результатом совершенствования методики расчета воздухоснабжения в данном аспекте являются сформулированные нами рекомендации регулирования темпа приращения рабочего аэродинамического давления.

Моделирование такого регулирования для скважины № 401 Куюмбинского месторождения приведено в табл. 4 и на рис. 3. Лимитирующими факторами служит условие репрессии на пласт и предотвращение пневморазрыва.

\begin{tabular}{|c|c|c|c|}
\hline \multirow[t]{2}{*}{$\begin{array}{c}\text { Глубина } \\
\text { интервала, } \\
\text { м } \\
\text { Interval } \\
\text { depth, m }\end{array}$} & $\begin{array}{c}\text { Пластовое } \\
\text { давление, } \\
\text { Formation } \\
\text { pressure, }\end{array}$ & $\begin{array}{c}\text { Фактические } \\
\text { давление гидро- } \\
\text { разрыва } \\
\text { Actual hydrofrac- } \\
\text { turing pressure }\end{array}$ & $\begin{array}{c}\text { Расчетное рабо- } \\
\text { чее давление } \\
\text { Calculated ope- } \\
\text { rating pressure }\end{array}$ \\
\hline & \multicolumn{3}{|c|}{$\mathrm{\kappa} \Gamma \mathrm{c} / \mathrm{cm}^{2} / \mathrm{kgf} / \mathrm{cm}^{2}$} \\
\hline 50 & 4,25 & 8,2 & 8 \\
\hline 100 & 8,5 & 16,4 & 15,9 \\
\hline 105 & 8,925 & 17,22 & 16 \\
\hline 150 & 12,75 & 21,45 & 16,24 \\
\hline 200 & 17 & 28,95 & 20,51 \\
\hline 250 & 21,25 & 36,45 & 25,1 \\
\hline 300 & 25,5 & 43,95 & 27,33 \\
\hline 350 & 29,75 & 51,45 & 31,88 \\
\hline 400 & 34 & 58,95 & 36,43 \\
\hline 450 & 38,25 & 66,45 & 41,7 \\
\hline 500 & 42,5 & 73,95 & 45,54 \\
\hline 550 & 46,75 & 81,45 & 50,1 \\
\hline
\end{tabular}

Таблица 4. Численные результаты расчета $P_{\text {раб }}$ для скважин Куюмбинского нефтяного месторождения

Table 4. Numerical results of $P_{o p}$ calculation for the wells at Kuyumbinskoe field

\section{Заключение}

Анализ результатов опытно-промышленных работ ударно-вращательного бурения интервалов скважин под кондуктор в технико-геологических условиях Куюмбинского месторождения позволил:

1) определить оптимальную зависимость для расчета коэффициента аэродинамического трения в методике Б.Б. Кудряшова на основе учета кинематической вязкости продуктов разрушения забоя, а также шероховатости обсаженного и открытого ствола скважины;

2) выявить характер изменения давления на компрессоре при увеличении расхода воздуха скважинных в условиях Куюмбинского месторождения; 


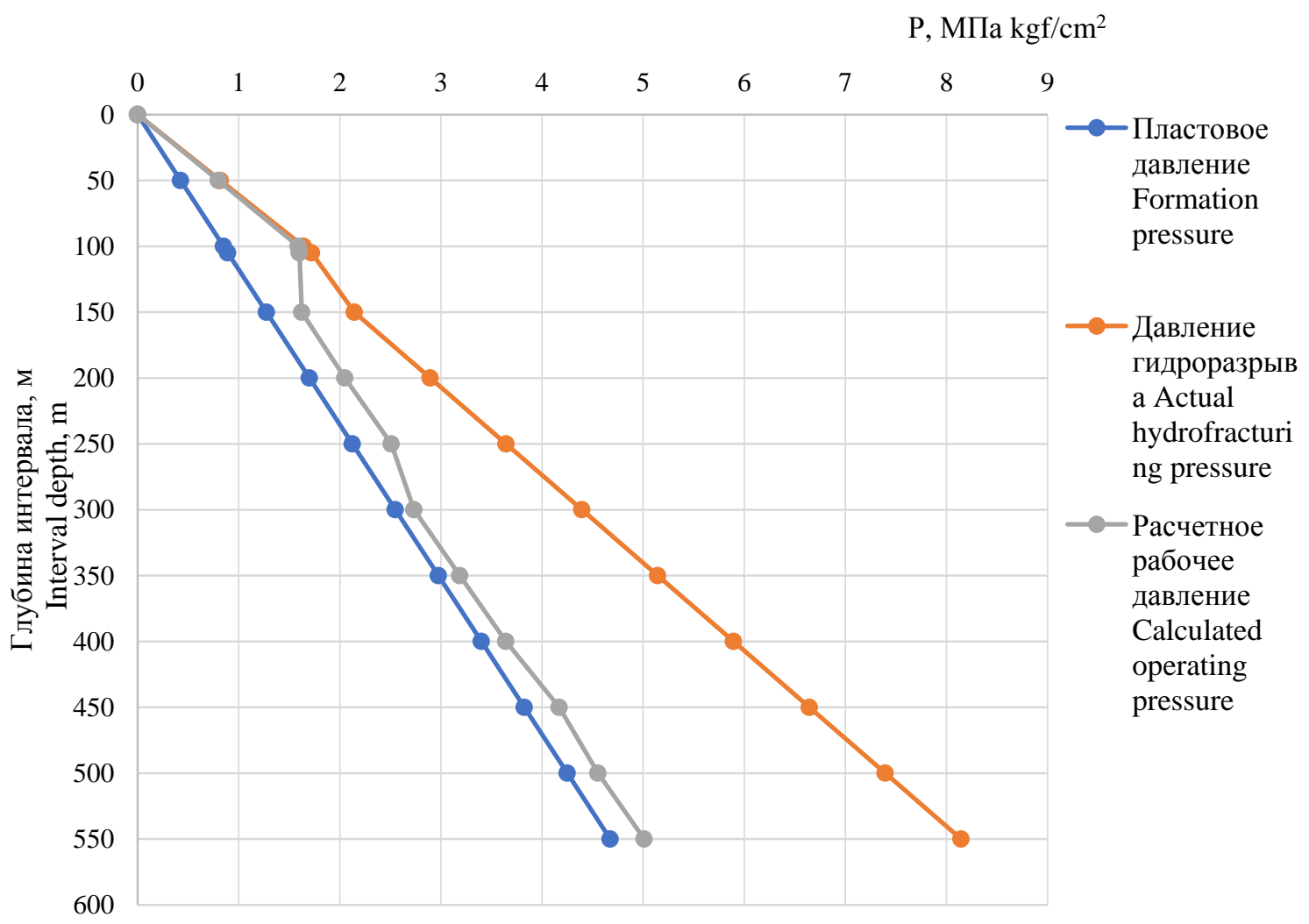

Pис. 3. Совмещенный график давлений с условием регулирования приращения $P_{\text {раб }}$ для секции кондуктора скважины № 401 Куюмбинского месторождения

Fig. 3. Overlay of pressures in the context of $P_{\text {op }}$ increase control for the surface casing interval in well no. 401 of Kuyumbinskoe field

3) сформулировать критериальную оценку безаварийности углубки скважины на основе поддержания оптимального значения расходной массовой концентрации шлама, предотвращая тем самым прихватоопасную ситуацию;

4) разработать основы методики регулирования параметров работы компрессорного оборудования и механической скорости проходки скважин с целью предотвращения разрыва горных пород.

Выполненный комплекс исследований и сформулированные дополнения к методике расчета воздухо-

\section{СПИСОК ЛИТЕРАТУРЫ}

1. Бузанов К.В., Борисов К.И. Обоснование и расчет параметров оборудования и распределения аэродинамических давлений при реализации пневмоударного бурения в геологических условия Чаяндинского месторождения // Вестник ассоциации буровых подрядчиков. - 2015. - № 4. - С. 9-15.

2. Бузанов К.В., Борисов К.И. Технология бурения пневмоудар ником как способ предупреждения катастрофических поглощений на Дулисьминском месторождении // Инженернефтяник. - 2014. - № 4 .- С. 28-31.

3. Бузанов К.В. Строительство вертикальных секций скважин с опережением в условиях Восточно-Сибирского региона с применением технологии ударно-вращательного бурения и очисткой забоя воздухом // Бурение и нефть. -2017 . - № 1 . C. 25-32.

4. Pletcher J., Scarr A. Application of air percussion drilling improves drilling efficiency in horizontal sandstone wells Society of Petroleum Engineers Annual Technical Conference and снабжения позволяют сделать шаги в применимости известной методики расчета воздухоснабжения скважины в новых технико-технологических условиях, тем самым расширив границы эффективности применения ударно-вращательного бурения при строительстве эксплуатационных и разведочных скважин на месторождениях углеводородов ВосточноСибирского региона, и могут служить научнометодической основой при проектировании программы работ в конкретных условиях хозяйствования.

Exhibition held. - Florence, Italy, 19-22 September 2010. P. 44-53.

5. Zhu H. Influence of relevant parameters on hole cleaning and pipe string erosion // Society of Petroleum Engineers Drilling Oil and Gas India Conference and Exhibition. - New Delhi, 20-22 January 2010. - P. 76-85.

6. Ванг Х. Итоги применения пневмоударного бурения в Керуй Групп // Нефть и Газ: 14 Международная выставка. - М., 30 июня 2017. - С. 61-68.

7. Земерев Е.С. Критическое истечение сыпучих материалов в пневмотранспортной системе подачи порошков: дис. ... канд. техн. наук. - Пермь, 2017. -116 с.

8. Кондратьев А.С., Ньа Т.Л. Основы расчета гидродинамических параметров при движении жидкости с монодисперсными крупными твердыми частицами в вертикальных трубах // Фундаментальные исследования. - 2016. - № 9. - С. 35-42.

9. Кудряшов Б.Б., Кирсанов А.И. Бурение разведочных скважин с применением воздуха. - М.: Недра, 1990. - 263 с. 
10. Malloy K.P. Air drilling in the presence of hydrocarbons: a time for pause // International Association of Drilling Contractors. Society of Petroleum Engineers Drilling Managed Pressure Drilling and Underbalanced Operations Conference and Exhibition. - Джакарта, Индонезия, 28-29 March 2007. - P. 97-103.

11. Air and gas drilling field guide / W.C. Lyons, B. Guo, R.L. Graham, G.D. Hawley. - UK, Oxford OX2 8DP: British Library Cataloguing-in-Publication Data, 2009. - 776 p.

12. Maranuk C. Unique system for underbalanced drilling using air in the Marcellus Shale // Society of Petroleum Engineers Eastern Regional Meeting. - Charleston, USA, 21-23 October 2014. P. 87-93.

13. Марон В.И. Гидравлика двухфазных потоков в трубопроводах. - СПб.: Изд-во «Лань», 2012. - 254 с.

14. Бузанов К.В. Разработка и совершенствование технологии безаварийного бурения интервалов под направления и кондукторы разведочных и эксплуатационных скважин на месторождениях Восточно-Сибирского региона (на примере Куюм- бинского нефтяного месторождения): дис. ...канд. техн. наук. - Томск, 2018. - $139 \mathrm{c}$.

15. Бронзов А.С. Бурение скважин с использованием газообразных агентов. - М.: Недра, 1989. - 288 с.

16. Климентов М.Н., Тиль В.И. Сооружение скважин ударновращательным способом бурения. - М.: Недра, 1986. -95 с.

17. Min Lu. Experimental and computational study of two-phase slug flow: a thesis submitted for degree of Doctor of Philosophy. London, 2015. $-346 \mathrm{p}$.

18. Vieira P. Minimum air and water flow rates required for effective cuttings transport in high angle and horizontal wells // International Association of Drilling Contractors. Society of Petroleum Engineers Drilling Conference. - Dallas, 26-28 February 2002. - P. 32-40.

19. Liu H. Experimental study on carrying capacity of cuttings in annulus for air/mist drilling // Society of Petroleum Engineers. Ico TA Coiled Tubing Roundtable. - Houston, 7-8 March 2001. P. 130-139.

Поступила 18.06.2019 2.

\section{Информация об авторах}

Бузанов К.В., кандидат технических наук, ассистент отделения нефтегазового дела Национального исследовательского Томского политехнического университета.

Борисов К.И., доктор технических наук, доцент, заведующий кафедрой бурения нефтяных и газовых скважин Сибирского федерального университета. 
UDC 622.24

\title{
IMPROVEMENT OF BOTTOM HOLE AIR CLEANING TO REDUCE ACCIDENT RATE OF WELL DRILLING AT KUYUMBINSKOE OILFIELD
}

\author{
Kirill V. Buzanov1, \\ byzanovaltay@mail.ru

\section{Konstantin I. Borisov²,} \\ kibor1956@gmail.com \\ 1 National Research Tomsk Polytechnic University, \\ 30, Lenin avenue, Tomsk, 634050, Russia. \\ 2 Siberian Federal University, \\ 79/10, Svobodny avenue, Krasnoyarsk, 660041, Russia.
}

The relevance of the research. The problem of washing fluid absorption during the construction of upper sections of production and exploration wells in the fields of Eastern Siberia is not new and is one of the main reasons for low rate of commercial drilling speed in the region. In addition, penetration of trouble intervals of wells requires considerable time and material costs. Air drilling is one of the promising solutions to the problem of absorption of washing liquid. The air drilling technique has been known for more than a hundred years, however, a new horizons of its application are opening up by the reason of the compressor's engineering progress. At the same time, it is necessary to adapt the existing methods of calculating air supply to the new mining and geological conditions for this technology. The paper introduces the main results of practical research in air cleaning of bottom hole during the drilling of the surface casing interval in the geological and economic context of Kuyumbinskoe oilfield.

The aim of the research is to study and develop a new methodology for trouble-free air drilling of intervals for directions and conductors in the construction cycle of production and exploration wells in fields in Eastern Siberia.

Object: the B.B. Kudryashov's method of calculating the air supply of the circulation system of a well.

Methods: combination of theoretical studies, mathematical modeling based on the basic principles of the theory of pneumatic transport, movement of dispersed particles in a carrier air stream and pilot works in real production conditions.

Results. The authors have stated the regulations that allow modifying the computational methodology for air supply to the well circulating system, the use of which will help prevent emergency situations at the design stage.

\section{Key words:}

Air cleaning of bottom hole, aerodynamic drag, B. Kudryashov's method, catastrophic loss of circulating fluid, control over drilling technique, aerodynamic pressure in a well.

\section{REFERENCES}

1. Buzanov K., Borisov K. Rationale and calculation of equipment parameters, distribution of aerodynamic pressures when using air percussion drilling in the geologic conditions of Chayandinskoye field. Drilling Contractors Association's Herald, 2015, no. 4, pp. 9-15. In Rus.

2. Buzanov K., Borisov K. Air percussion drilling as a way to prevent catastrophic fluid loss at Dulisminskoye field. Petroleum Engineer, 2014, no. 4, pp. 28-31. In Rus.

3. Buzanov K. Advanced drilling of vertical well intervals in the conditions of East Siberia using percussion rotary drilling and air cleaning of bottom hole. Drilling and Oil, 2017, no. 1, pp. 25-32. In Rus.

4. Pletcher J., Scarr A. Application of air percussion drilling improves drilling efficiency in horizontal sandstone wells. Society of Petroleum Engineers Drilling Annual Technical Conference and Exhibition. Florence, Italy, 19-22 September 2010. pp. 44-53.

5. Zhu H. Influence of relevant parameters on hole cleaning and pipe string erosion. Society of Petroleum Engineers Oil and Gas India Conference and Exhibition. New Delhi, 2010, 20-22 January. pp. 76-85.

6. Wang H. Itogi primeneniya pnevmoudarnogo bureniya v Keruy Grupp [Results of applying pneumatic percussion drilling in the Kerui group]. Naft i gaz: 14 Mezhdunarodnaya vystavka $\left[14^{\text {th }} \mathrm{In}-\right.$ ternational Oil and Gas Exhibition]. Moscow, 2017, June 30. pp. 61-68.

7. Zemerev E.S. Kriticheskoe istechenie sypuchikh materialov v pnevmotransportnoy sisteme podachi poroshkov. Dis. Kand. nauk [Critical flow of bulk materials in the pneumotransport powder supply system. Cand. Diss.]. Perm, 2017. 116 p.

8. Kondratyev A.S., Nya T.L. Basis of calculation of hydrodynamic parameters of fluid movement with monodispersed large solids in vertical pipes. Fundamental Research, 2016, no. 9, pp. 35-42. In Rus.

9. Kudryashov B.B., Kirsanov A.I. Burenie razvedochnykh skvazhin s primeneniem vozdukha [Drilling of exploration wells using air]. Moscow, Nedra Publ., 1990. 263 p.

10. Malloy K.P. Air drilling in the presence of hydrocarbons: a time for pause. International Association of Drilling Contractors. Society of Petroleum Engineers Drilling Managed Pressure Drilling and Underbalanced Operations Conference and Exhibition. Djakarta, Indonesia, 28-29 March 2007. - P. 97-103.

11. Lyons W.C., Guo B., Graham R.L., Hawley G.D. Air and gas drilling field guide. UK, Oxford OX2 8DP, British Library Cataloguing-in-Publication Data, 2009. 776 p.

12. Maranuk C. Unique system for underbalanced drilling using air in the Marcellus Shale. Society of Petroleum Engineers Eastern Regional Meeting. Charleston, USA, 2014, 21-23 October. pp. 87-93.

13. Maron V. Gidravlika dvukhfaznykh potokov v truboprovodakh [Hydraulics of two-phase flows in pipelines]. St.-Petersburg, Lan Publ. house, 2012. $254 \mathrm{p}$.

14. Buzanov K. Razrabotka $i$ sovershenstvovanie tekhnologii bezavariynogo burenia intervalov pod napravlenie i konduktory razvedochnykh $i$ expluatasionnykh skvazhin na mestorozhdeniakh Vostochno-Sibirskogo regiona (na primere Kuymbinskogo neftyanogo mestorozhdenia). Dis. Kand. nauk [Development and improvement of accident-free technology for drilling of conductor and surface casing intervals for exploration and production wells in East-Siberia (case study: Kuyumbinskoe oilfield). Cand. Diss.]. Tomsk, 2018. $139 \mathrm{p}$.

15. Bronzov A.S. Burenie skvazhin s ispolzovaniem gazoobraznykh agentov [Drilling wells with gaseous agents]. Moscow, Nedra Publ., 1989. 288 p. 
16. Klimentov M., Til V. Sooruzhenie skvazhin udarno-vrashchatelnym sposobom bureniya [Percussion rotary drilling of wells]. Moscow, Nedra Publ., 1986. 95 p.

17. Min Lu. Experimental and computational study of two-phase slug flow: a thesis submitted for degree of Doctor of Philosophy. London, $2015.346 \mathrm{p}$.

18. Vieira P. Minimum air and water flow rates required for effective cuttings transport in high angle and horizontal wells. International
Association of Drilling Contractors. Society of Petroleum Engineers Drilling Conference. Dallas, 2002, 26-28 February. pp. 32-40.

19. Liu H. Experimental study on carrying capacity of cuttings in annulus for air/mist drilling. Society of Petroleum Engineers. Ico TA Coiled Tubing Roundtable. Houston, 2001, 7-8 March. pp. 130-139.

\section{Information about the authors}

Kirill V. Buzanov, Cand. Sc., assistant, National Research Tomsk Polytechnic University.

Konstantin I. Borisov, Dr. Sc., associate professor, head of department, Siberian Federal University. 